\title{
Functional changes of airway epithelial cells and mitochondria in rat models of asthenic lung and phlegm blocking combined with cough variant asthma
}

\author{
HUIFANG LIU ${ }^{1}$, SIMING TAO ${ }^{2}$, HONGXIA MA ${ }^{2}$, JING JIN ${ }^{3}$, \\ JING JING ${ }^{2}$, LI YAO ${ }^{4}$, XIULAN MA ${ }^{5}$ and FENGSEN $\mathrm{LI}^{2}$ \\ ${ }^{1}$ Department of Internal Medicine, Xinjiang Medical University; ${ }^{2}$ Pneumology Department, The Affiliated Traditional \\ Medical Hospital of Xinjiang Medical University; ${ }^{3}$ Internal Medicine of TCM, The First Affiliated Hospital \\ of Xinjiang Medical University; ${ }^{4}$ Pharmacy Department and ${ }^{5}$ AIDS Research Office, The Affiliated Traditional \\ Medical Hospital of Xinjiang Medical University, Urumqi, Xinjiang 830000, P.R. China
}

Received March 27, 2018; Accepted September 14, 2018

DOI: $10.3892 /$ etm.2018.6863

\begin{abstract}
The aim of this study was to investigated the functional changes of airway epithelial cells and mitochondria in rat models of asthenic lung and phlegm blocking combined with cough variant asthma (CVA). Sixteen Sprague-Dawley rats were randomly divided into two groups: Control and model group, with 8 rats in each group. On the basis of the CVA rat model induced and sensitized by ovalbumin and aluminum hydroxide, the rat models with asthenic lung and phlegm blocking combined with CVA were established via smoking stimulation. The rats in the control group were injected with equivalent normal saline. All rats were sacrificed after the model was successfully prepared. The lung histopathological sections of the two groups of rats were observed, and respiratory control ratio (RCR) of mitochondria and membrane potential changes were compared. The results showed that the rats in the model group had tracheal structure abnormities, epithelial cell damages, cilia structure defects, capillary injection, alveolar exudates, and inflammatory cells compared to those in the control group. RCR of mitochondria and membrane potential of rats in the model group were significantly lower than those of rats in the control group $(\mathrm{P}<0.05)$. Damaged lung tissue and decreased mitochondrial activity and membrane potential are detected in the rat models of asthenic lung and phlegm blocking combined with CVA.
\end{abstract}

Correspondence to: Dr Fengsen Li, Pneumology Department, The Affiliated Traditional Medical Hospital of Xinjiang Medical University, 116 Huanghe Road, Urumqi, Xinjiang 830000, P.R. China E-mail: fengsen602@163.com

Key words: asthenic lung and phlegm blocking, cough variant asthma, airway epithelial cells, mitochondria

\section{Introduction}

The main clinical manifestations of cough variant asthma (CVA) include recurrent episode of chronic cough with no obvious wheezing, shortness of breath, and other typical asthma symptoms, but its pathogenesis is the same with that of asthma, and both show inflammation $(1,2)$. According to the clinical manifestations of CVA, it is named 'anemogenous cough' in Chinese traditional medicine. 'Wind' has internal and external meanings: Endogenous wind lies in liver, and exogenous wind lies in lung (3). It is believed in traditional Chinese medicine that the dispersing, purification and descending functions of lung $q i$ regulate the metabolism through the modulating of the pathway of water metabolism in the body. The dysfunction of lung $q i$ will stop the water metabolism of the body, which accumulated and turned into phlegm, and as a result the asthenic lung and phlegm blocking causes a cough (4). This study, based on the establishment of rat models of asthenic lung and phlegm blocking combined with CVA, investigated functional changes of rat airway epithelial cells and mitochondria, in order to discover the pathogenesis of CVA, providing scientific guidance for clinical treatment of CVA.

\section{Materials and methods}

Experimental animals. A total of 16 four-week-old specific pathogen free (SPF) rats weighing $100 \pm 10 \mathrm{gr}$ (half males and half females) were bought and then fed adaptively with normal food. During the feeding process, the humidity was maintained at 50-65\%, alternated day and night, drink any water and eat any food. One week later, they were divided into two groups (control and model group) according to the random number table. There were 8 rats in each group. The study was approved by the Ethics Committee of Xinjiang Medical University (Urumqi, China).

Modeling methods and experimental methods. Model group: Rats in the model group were made into CVA models via the stimulation and sensitization of ovalbumin (OVA) in 

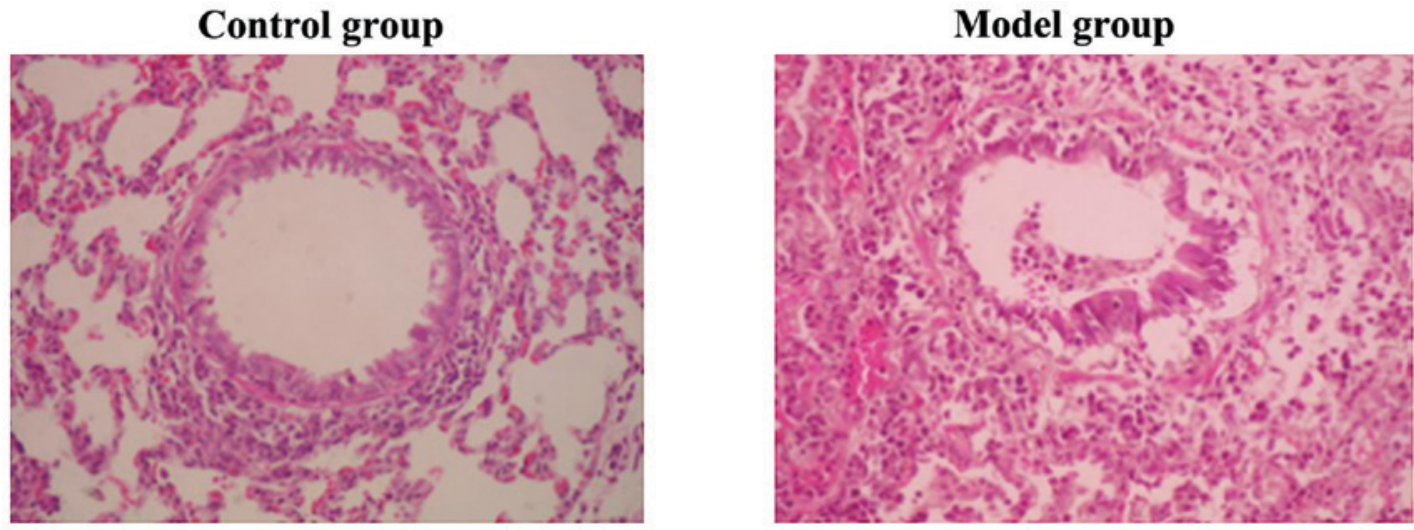

Figure 1. HE staining of lung issue of rats. Both are observed under the microscope with the amplification of X200. HE, hematoxylin and eosin.

cooperation with aluminum hydroxide. They were injected intraperitoneally with $1 \mathrm{ml}$ sensitizer (containing $1 \mathrm{mg}$ OVA and $10 \mathrm{mg}$ aluminum hydroxide) every other day, 7 times in total. On this basis, the rats were placed in a smoky cabinet with moxa ignited (containing $0.2 \mathrm{~g}$ of sulfur powder). After $2 \mathrm{~h}$ of burning, the rats were removed. This operation was performed twice per day for 40 days. Judging criteria for the successful model: i) The rats coughed or coughed with the buzzing sound obviously, ii) the animals gained weight slowly, were short of breath and slow-moving, and had dry hair and iii) the secretion of phlegm was active $(5,6)$.

Control group: Rats in the control group adopted free diet without any intervention except the daily injection of equivalent normal saline.

Within $24 \mathrm{~h}$ after the last stimulation experiment, all rats were anesthetized with $3.5 \%$ chloral hydrate $(1 \mathrm{ml} / 100 \mathrm{~g})$ and sacrificed via femoral artery blood-letting. After that, fur, muscle, and sternum were peeled off layer by layer, and the trachea, bronchus, and lungs were removed and preserved at $-80^{\circ} \mathrm{C}$ in liquid nitrogen.

Separation and cultivation of airway primary epithelia of rats. A part of the trachea was taken, and the mucosal debris on the surface was carefully removed. Then, the trachea was placed in phosphate-buffered saline (PBS) digestive juice containing $0.5 \mathrm{mg} / \mathrm{ml}$ protease, followed by digestion at $4^{\circ} \mathrm{C}$ overnight and centrifugation at $180 \mathrm{x} \mathrm{g}$ for $5 \mathrm{~min}$ at $4^{\circ} \mathrm{C}$. After that, the enzyme-containing supernatant was discarded, and the enzyme reaction was stopped. After $2 \mathrm{ml}$ of PBS solution was added to wash twice, airway epithelial cells were dispersed in Dulbecco's modified Eagle's medium (DMEM) containing 5\% fetal bovine serum, inoculated into a $100 \mathrm{ml}$ culture dish, and cultured at $37^{\circ} \mathrm{C}$ and $5 \% \mathrm{CO}_{2}$.

\section{Observation indicators.}

Pathological observation of lung tissue. Hematoxylin and eosin (HE) staining: After another part of tracheal tissue was put into $4 \%$ paraformaldehyde for $48 \mathrm{~h}$ of fixation, tissue was dehydrated with gradient ethanol (50, 70, 80, 90 and 100\%), cleared in xylene, wax-infiltrated and embedded in paraffin. Then, the sample was frozen and sliced with a paraffin section cutter, and preserved under room temperature after drying. The sections were dewaxed three times successively with xylene, soaked in gradient ethanol (volume ratio: 100, $90,80,70$ and $50 \%$ ) and immersed in distilled water for 20 min, followed by staining. Nuclear was stained with the hematoxylin for $30 \mathrm{~min}$ and rinsed three times with water. After the color separation with a mixture of hydrochloride and ethanol for 5-10 sec and the sample bluing with water for 15 min, staining results were observed by naked eye. Eosin staining was performed for $6 \mathrm{sec}$, and the staining effect was observed under a microscope (Olympus Corporation, Tokyo, Japan). After the dyeing was completed, the mixture was dehydrated with a gradient ethanol (50, 80, 90 and 100\%) and cleared in xylene. Finally, the sections were sealed with neutral resin. The morphology of the sections was observed under a microscope (Olympus Corporation).

Determination of mitochondrial respiratory control ratio $(R C R)$ in airway epithelial cells. With succinic acid as the reaction substrate, based on the results of the presence of adenosine diphosphate (ADP) in mitochondria detected by a RCR quantitative detection kit, the slopes of the respiratory state 3 and respiratory of state 4 were determined. The ratio of two slopes is RCR.

Determination of mitochondrial membrane potential in airway epithelial cells. The separated airway epithelial cells were added to rhodamine 123 stock solution $(1 \mathrm{~g} / \mathrm{l})$, incubated at $37^{\circ} \mathrm{C}$ in the dark for $45 \mathrm{~min}$, and then fixed with $70 \%$ cold ethanol. The changes of mitochondrial membrane potential were measured by flow cytometer (FCM).

Statistical analysis. Statistical Product and Service Solutions 17.0 software (SPSS Inc., Chicago, IL, USA) was used to analyze the data. Measurement data were compared using the t-test method between the two groups of data. The results were expressed as mean $\pm \mathrm{SD}$. Enumeration data were compared using the Chi-square test. $\mathrm{P}<0.05$ was considered to indicate a statistically significant difference.

\section{Results}

Pathology observation of lung tissue. The situation of trachea, epithelial cell morphology, cilia status, capillaries, and alveolar between two groups of rats were observed (Fig. 1), and the lung tissues between two groups of rats were observed and compared (Table I). 
Table I. Observation and comparison of lung tissue in two groups of rats.

\begin{tabular}{lll}
\hline Groups & \multicolumn{1}{c}{ Control } & \multicolumn{1}{c}{ Model } \\
\hline $\begin{array}{l}\text { Tracheal structure } \\
\text { Epithelial cell } \\
\text { morphology }\end{array}$ & $\begin{array}{l}\text { Normal } \\
\text { Arranged in line }\end{array}$ & $\begin{array}{l}\text { Abnormal } \\
\text { Injured }\end{array}$ \\
Cilia status & $\begin{array}{l}\text { No lodging } \\
\text { and deletion }\end{array}$ & $\begin{array}{l}\text { With lodging } \\
\text { and deletion }\end{array}$ \\
Capillaries & $\begin{array}{l}\text { No hyperemia } \\
\text { and ischemia }\end{array}$ & $\begin{array}{l}\text { Hyperemia } \\
\text { and ischemia }\end{array}$ \\
Alveolar & $\begin{array}{l}\text { No exudate } \\
\text { No inflammatory }\end{array}$ & $\begin{array}{l}\text { With exudate } \\
\text { Accompanied by } \\
\text { Other }\end{array}$ \\
cell infiltration & $\begin{array}{l}\text { inflammatory } \\
\text { cell infiltration }\end{array}$ \\
& & \\
\hline
\end{tabular}

Table II. Comparison of the measurement of mitochondrial RCR in airway epithelial cells of two groups.

\begin{tabular}{lc}
\hline Groups & RCR \\
\hline Control & $2.60 \pm 0.13$ \\
Model & $2.00 \pm 0.11$ \\
t & 10.040 \\
P-value & $0.001^{\mathrm{a}}$ \\
\hline
\end{tabular}

${ }^{\mathrm{a}} \mathrm{P}<0.05$, compared to the control group. RCR, respiratory control ratio.

Table III. Comparison of the measurement of mitochondrial membrane potential in airway epithelial cells between two groups.

\begin{tabular}{lc} 
Groups & $\begin{array}{c}\text { Mitochondrial membrane } \\
\text { potential }(\mathrm{mV})\end{array}$ \\
\hline Control & $67.63 \pm 3.20$ \\
Model & $56.38 \pm 2.33$ \\
$\mathrm{t}$ & 8.036 \\
P-value & $0.001^{\mathrm{a}}$ \\
\hline
\end{tabular}

${ }^{\mathrm{a}} \mathrm{P}<0.05$, compared to the control group.

Results of mitochondrial RCR in airway epithelial cells. The RCR in the control group was $2.60 \pm 0.13$, which was signifi-

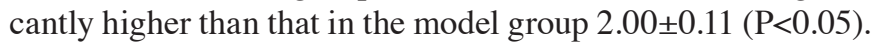
Therefore, it was believed that the mitochondrial RCR of rats with asthenic lung and phlegm blocking combined with CVA was significantly decreased (Table II).

Measurement of mitochondrial membrane potential in airway epithelial cells. The mitochondrial membrane potential of airway epithelial cells in the control group was $67.63 \pm 3.20 \mathrm{mV}$, which was significantly higher than that in the model group $56.38 \pm 2.33 \mathrm{mV}(\mathrm{P}<0.05)$. Therefore, it was believed that the mitochondrial membrane potential of the rat with asthenic lung and phlegm blocking combined with CVA was significantly decreased (Table III).

\section{Discussion}

The lung plays a significant role in the fluid balance of the human body. It is stated in the Meridian Theory that 'The adjustment of the waterway of human body depends on the lung'. Once the lung functions are incomplete, the body will show the disorder of metabolism of fluid. Among them, phlegm is a pathological product of body fluid metabolism disorders. CVA is due to the invasion of exogenous pathogens, eating disorders, deficiency of lung and spleen (7), pulmonary loss of dispersing and descending functions, liquid stopped and turned into phlegm, asthenic lung and phlegm blocking. In this study, rats were repeatedly stimulated by smoking to cause chronic cough, loss of lung $q i$, water imbalance, and water stasis (8), which was consistent with the clinical manifestations of CVA patients. There are two main reasons for choosing the CVA rat model in this experiment. One is that rat asthma model is highly recognized worldwide, and the second is that the rat better replicates the characteristics of human asthma in comparison with guinea pigs, mice and other experimental animals. In this experiment, a rat model of asthenic lung and phlegm blocking combined with CVA was established, and the changes of airway epithelial cells and mitochondrial functions between model rats and normal rats were observed, in order to be able to elucidate the pathogenesis of CVA so as to provide scientific guidance for clinical CVA treatment.

As known, the integrity of the lung tissue structure is an important basis for normal respiratory function. The results of this study showed that the rats in the model group had abnormal lung structure, which mainly includes abnormal tracheal structure, damaged epithelial cells, defective cilia structure, capillaries congestion, and exudate in the alveoli. Epithelial cell damage is a characteristic pathological change in asthma, which may be caused by persistent chronic inflammation $(8,9)$. Furthermore, inflammatory cells are indeed observed on lung histopathological sections. But the inflammation was not observed in the control rats. Airway epithelial cells mainly act as a defense against the virus, and damage to epithelial cells causes invasion of exogenous pathogens into the body and occurrence of exudate in the airways. At present, studies have shown that essentially, CVA is a disease caused by airway inflammation, which involves inflammatory cells such as eosinophils, lymphocytes, and mast cells, inflammatory mediators, and cytokines.

Mitochondria can produce endogenous reactive oxygen and energy and are closely related to asthma. It has been reported in the literature that dysfunction of mitochondrial function in epithelial cells can increase the incidence of airway inflammation (10). With the presence of reactive oxygen, mitochondria convert glucose in the body into energy through the tricarboxylic acid cycle. In this process, RCR reflects the difference in the solubility of living mitochondria in the presence of ADP, which reflects the integrity of mitochondrial 
structure and function, as well as oxidative phosphorylation efficiency (11). The higher the RCR is, the stronger the mitochondrial activity is. The experimental results indicated that the mitochondrial activity of the model group rats was clearly decreased compared with that in the control group. The proton pump on the inner mitochondrial membrane pumps the protons in the matrix into the interstitial space. A large number of protons are accumulated in the interstitial space, and a proton gradient is formed. Therefore, there are a large number of positive charges outside the mitochondrial inner membrane, and a large number of negative charges, which turn into positive membrane potential outside and negative inside $(12,13)$. The normal membrane potential is the prerequisite for maintaining mitochondrial oxidative phosphorylation and ATP formation (14). The results show that the mitochondrial membrane potential of the model group rats is significantly decreased, and it can be proven that the mitochondrial activity of rat with asthenic lung and phlegm blocking combined with CVA decreased.

In conclusion, compared to normal rats, rat models of asthenic lung and phlegm blocking combined with CVA have abnormal lung tissue and epithelial cell damage. This is the pathogenesis of chronic inflammation and exudative fluid in the lung tissue. In addition, asthma can be treated by using drugs that can improve mitochondrial structure or function due to its close relation with mitochondrial dysfunction.

\section{Acknowledgements}

Not applicable.

\section{Funding}

This study was funded by the Natural Science Fund Projects of Xinjiang Uyghur Autonomous Region (no. 2017D01C175).

\section{Availability of data and materials}

The datasets used and/or analyzed during the present study are available from the corresponding author on reasonable request.

\section{Authors' contributions}

HL drafted the manuscript and helped in the construction of CVA models. ST and HM were responsible for separation and cultivation of airway primary epithelia of rats. JJin analyzed pathological features of lung tissue. LY and JJing contributed to RCR quantitative detection. XM and FL were responsible for flow cytometer assay. All authors read and approved the final study.

\section{Ethics approval and consent to participate}

The study was approved by the Ethics Committee of Xinjiang Medical University (Urumqi, China).

\section{Patient consent for publication}

Not applicable.

\section{Competing interests}

The authors declare that they have no competing interests.

\section{References}

1. Takemura M, Niimi A, Matsumoto H, Ueda T, Matsuoka H, Yamaguchi M, Jinnai M, Chin K and Mishima M: Clinical, physiological and anti-inflammatory effect of montelukast in patients with cough variant asthma. Respiration 83: 308-315, 2012.

2. Shimoda T, Obase Y, Kishikawa R, Iwanaga T, Miyatake A and Kasayama S: The fractional exhaled nitric oxide and serum high sensitivity C-reactive protein levels in cough variant asthma and typical bronchial asthma. Allergol Int 62: 251-257, 2013.

3. Wang P, Wu XY, Zhang ML, Tian DZ and Liu SL: Expression of NF-kappaB and COX-2 mRNA in rats with phlegm obstruction due to lung-deficiency. J Chin Integr Med 3: 119-122, 2005 (In Chinese).

4. Liu S, Hua YQ, Sun ZP, Tan S and Lu DM: Breast cancer pathogenesis of stagnation of phlegm, poison and blood stasis: Rationale and clinical application in traditional in traditional Chinese medicine. J Chin Integr Med 5: 122-125, 2007 (In Chinese).

5. Miao Q, Wei PC, Fan MR and Zhang YP: Clinical study on treatment of cough variant asthma by Chinese medicine. Chin J Integr Med 19: 539-545, 2013.

6. Nishitsuji M, Fujimura M, Oribe Y and Nakao S: Effect of montelukast in a guinea pig model of cough variant asthma. Pulm Pharmacol Ther 21: 142-145, 2008.

7. Lougheed MD, Turcotte SE and Fisher T: Cough variant asthma: Lessons learned from deep inspirations. Hai 190: 17-22, 2012.

8. Kim MS, Cho KA, Cho YJ and Woo SY: Effects of interleukin-9 blockade on chronic airway inflammation in murine asthma models. Allergy Asthma Immunol Res 5: 197-206, 2013.

9. Cai LQ, Zhang JY, Yu CX and Zhu L: rhPLD2 suppresses chronic inflammation reactions in a guinea pig asthma model. Immunopharmacol Immunotoxicol 34: 74-78, 2012.

10. Karaman M, Firinci F, Cilaker S, Uysal P, Tugyan K, Yilmaz O, Uzuner $\mathrm{N}$ and Karaman O: Anti-inflammatory effects of curcumin in a murine model of chronic asthma. Allergol Immunopathol (Madr) 40: 210-214, 2012.

11. Harrison DK, Fasching M, Fontana-Ayoub $M$ and Gnaiger E: Cytochrome redox states and respiratory control in mouse and beef heart mitochondria at steady-state levels of hypoxia. J Appl Physiol (1985) 119: 1210-1218, 2015.

12. Martínez-Reyes I, Diebold LP, Kong H, Schieber M, Huang H, Hensley CT, Mehta MM, Wang T, Santos JH, Woychik R, et al: TCA cycle and mitochondrial membrane potential are necessary for diverse biological functions. Mol Cell 61: 199-209, 2016.

13. Sanderson TH, Reynolds CA, Kumar R, Przyklenk K and Hüttemann M: Molecular mechanisms of ischemia-reperfusion injury in brain: Pivotal role of the mitochondrial membrane potential in reactive oxygen species generation. Mol Neurobiol 47: 9-23, 2013.

14. Sureda FX, Escubedo E, Gabriel C, Comas J, Camarasa J and Camins A: Mitochondrial membrane potential measurement in rat cerebellar neurons by flow cytometry. Cytometry $28: 74-80$, 1997.

This work is licensed under a Creative Commons Attribution-NonCommercial-NoDerivatives 4.0 International (CC BY-NC-ND 4.0) License. 